\title{
SELF-MONITORING AND PEER FEEDBACK STRATEGIES: CHALLENGES AND OPPORTUNITIES IN THE EFL WRITING CLASS
}

\author{
Thanakorn Weerathai \\ Rajamangala University of Technology Isan, Khon Kaen Campus (Thailand)
}

\begin{abstract}
Although learning paradigm has shifted from teacher-centered to student-centered for more than a decade, where students are encouraged to be left independent and able to learn writing collaboratively, the teaching and learning in the EFL writing context still poses many problems. The problems can be students' lack of proper understanding of the writing skill; language knowledge limitation; ambiguity of feedback; and low self-efficacy for writing. These are factors that affect how students perform in their writing as well as on their ability to think critically. This study aimed to explore students' attitudes toward the implementation of the self-monitoring and peer feedback strategies in the EFL essay writing class using a four-point Likert scale attitude questionnaire and semi-structured interview as instruments. Participants were 30 mixed-ability third-year undergraduate students majoring in English for International Communication at a university in the northeastern region of Thailand. Findings revealed that students had positive attitudes toward these two strategies, stating that it helped them to learn via social process and to gradually develop their critical thinking skills. This paper, based on the data, concluded that challenges in implementing the self-monitoring and peer feedback strategies in the writing class where the majority of students were in the low-intermediate level due to lack of proper understanding of the characteristics of the writing skill and of learning how to write; due to possible low self-efficacy for writing and collaborating with peers due to their limitation of language knowledge.
\end{abstract}

Keywords: Self-monitoring, peer feedback, EFL writing.

\section{Introduction}

\subsection{Background}

Many different approaches and strategies to writing instruction have been sought out to enhance students' writing performance and foster their independence and collaboration in learning writing. Self-monitoring and peer feedback are among those strategies. However, the self-monitoring strategy is found to most benefit students of a high-proficiency level (Chen, 2009; Xiang, 2004), while the peer feedback strategy is likely to most benefit students of the same proficiency level or higher (Gielen, Peeters, Dochy, Onghena \& Struyven, 2010; Rollinson, 2005; Yu \& Hu, 2016). This instance is often witnessed in many EFL writing classes where the students' langauge abilities are mixed making it quite challenging to couple and implement these two strategies. In the context of teaching and learning writing in Thailand, teachers and educators attempt to seek for effective methods to minimize such a problem; however, very few studies have been found to come with possible variables that may affect the implementation of the self-monitoring and peer feedback strategies with mixed-ability students in essay writing classes in Thailand.

\subsection{Purpose of study}

As mixed-ability students are commonly seen in most writing classes and it is rare to find studies conducted on the self-monitoring coupled with peer feedback strategies in an essay writing class in Thailand, there is an urgent need to find out challenges and opportunities of the implementation of these two important writing strategies. Thus, this study was to explore students' attitudes toward the implementation of the self-monitoring and peer feedback strategies in an essay writing class in order to shed light in the EFL writing context. 


\section{Methods}

\subsection{Research design and participants}

This study was mixed-methods. A four-point Likert scale and semi-structured interview were used as instruments to find out how students viewed the strategies after attending a 14-week course of study. Participants were 30 mixed-ability third-year undergraduate students majoring in English for International Communication at a university in the northeastern region of Thailand, aged 20-23 including male and female. The English writing proficiency of most students was at the intermediate and low levels.

\subsection{Data collection}

The questionnaire was distributed to thirty students at the end of the course of study. It took about 10-15 minutes for the students to complete the questionnaires. All questionnaires were returned $(100 \%)$. Moreover, the semi-structured interview was conducted with nine students including three high, three intermediate, and three low-proficiency students. The interviewees were asked to report and elaborate their views in Thai regarding the implementation of the two strategies. Each interview took about 20 minutes. All interviews were audio recorded.

\subsection{Data analysis}

The criteria of the questionnaire was set prior to the analysis to interpret the data. The data were interpreted as follows:

$$
\begin{array}{ll}
1=\text { strongly disagree }(1.0-1.49) & 2=\text { disagree }(1.5-2.49) \\
3=\operatorname{agree}(2.5-3.49) & 4=\text { strongly agree }(3.5-4.0)
\end{array}
$$

Data obtained from the questionnaires were calculated by using descriptive statistics. The statistical methods used to analyze the data were as follows:

1. Percentage was used to show a proportionate part of a total of the questionnaire. It allowed the participants to rate their agreements and disagreements using four-point Likert scale.

2. Arithmetic mean was used to calculate the average level of agreements or disagreements of the questionnaire.

3. The standard deviation was used to investigate how much variance there was in the mean.

In addition, data gained from the semi-structured interviews were analyzed using content analysis. Data were transcribed and later categorized into three aspects: self-monitoring strategy, peer feedback strategy, and additional comments and suggestions. After that, the differences and similarities of the responses toward the questions were tallied and reported.

\section{Results}

Regarding the results of the questionnaires, it was found that many $(72.5 \%)$ felt that they liked the self-monitoring strategy. The strategy was important in the writing class $(79.25 \%)$ and it helped them $(75.75 \%)$ improve their essay writing skills. Many $(78.25 \%)$ also reported that the strategy helped them read more critically and ask better questions in the same percentage, but many $(72.5 \%)$ thought that it was a difficult strategy and that they $(65.75 \%)$ felt confident using the strategy.

As for the peer feedback strategy, conversely, most $(80.75 \%)$ felt that they liked the strategy and were confident giving peer feedback $(71.75 \%)$. Some $(65 \%)$ thought that it was a difficult strategy. The strategy was important in the writing class $(81.75 \%)$ and it helped them $(81.75 \%)$ improve their essay writing skills. Moreover, the strategy helped most of them think more critically (83.25\%) and learn collaboratively $(81.75 \%)$. Table 1 illustrates the results of the questionnaires.

Table 1. Students' attitudes toward the self-monitoring and peer feedback strategies.

\begin{tabular}{|l|l|l|l|}
\hline \multicolumn{1}{|c|}{ Students' attitudes } & Mean & SD & Percentage \\
\hline $\begin{array}{l}\text { Self-monitoring strategy } \\
\text { 1. I like self-monitoring strategy. }\end{array}$ & 2.90 & 0.48 & 72.50 \\
\hline 2. I feel confident when self-monitoring. & 2.63 & 0.72 & 65.75 \\
\hline 3. Self-monitoring is an important strategy in a process writing course. & 3.17 & 0.53 & 79.25 \\
\hline $\begin{array}{l}\text { 4. Self-monitoring is a difficult strategy. } \\
\begin{array}{l}\text { 5. Self-monitoring strategy makes me feel more confident and motivated } \\
\text { in writing. }\end{array}\end{array}$ & 2.90 & 0.55 & 72.50 \\
\hline
\end{tabular}




\begin{tabular}{|l|l|l|l|}
\hline \multicolumn{1}{|c|}{ Students' attitudes } & Mean & SD & Percentage \\
\hline 6. Self-monitoring strategy helps me improve my essay writing skills. & 3.03 & 0.49 & 75.75 \\
\hline 7. Self-monitoring strategy helps me read more critically. & 3.13 & 0.43 & 78.25 \\
\hline $\begin{array}{l}\text { 8. Self-monitoring strategy helps me ask better questions from my } \\
\text { writing. }\end{array}$ & 3.13 & 0.57 & 78.25 \\
\hline 9. Self-monitoring strategy helps me learn to be autonomous. & 3.10 & 0.55 & 77.50 \\
\hline 10. Self-monitoring strategy helps me get specific feedback. & 3.07 & 0.52 & 76.75 \\
\hline 11. I will use self-monitoring strategy in my future writing. & 2.97 & 0.56 & 74.25 \\
\hline $\begin{array}{l}\text { Peer feedback strategy } \\
\text { 12. I like peer feedback strategy. }\end{array}$ & 3.23 & 0.57 & 80.75 \\
\hline 13. I feel confident when giving feedback to peers. & 2.87 & 0.73 & 71.75 \\
\hline 14. Peer feedback is an important strategy in a process writing course. & 3.27 & 0.45 & 81.75 \\
\hline 15. Peer feedback is a difficult strategy. & 2.60 & 0.56 & 65.00 \\
\hline $\begin{array}{l}\text { 16. Peer feedback strategy makes me feel more confident and motivated } \\
\text { in writing. }\end{array}$ & 3.17 & 0.53 & 79.25 \\
\hline $\begin{array}{l}\text { 17. Peer feedback strategy helps me build rapport and relationship with } \\
\text { friends. }\end{array}$ & 3.27 & 0.52 & 81.75 \\
\hline 18. Peer feedback strategy helps me improve my essay writing skills. & 3.27 & 0.52 & 81.75 \\
\hline 19. Peer feedback strategy helps me think more critically. & 3.33 & 0.48 & 83.25 \\
\hline 20. Peer feedback strategy helps me learn collaboratively. & 3.27 & 0.52 & 81.75 \\
\hline 21. Peer feedback strategy helps me understand problems in my writing. & 3.30 & 0.53 & 82.50 \\
\hline 22. I will use peer feedback strategy in my future writing. & 3.27 & 0.52 & 81.75 \\
\hline
\end{tabular}

Based on the results of the interviews, it was found that most of them reported that the self-monitoring strategy was difficult, but useful. The high-proficiency students stated that although the self-monitoring was a difficult strategy, it did help them think more deeply and be more careful of all writing aspects. The strategy fostered them to be more critical and careful when reading and writing their own work. It also helped them feel more confident in writing. With critical reading skills, the students learned to evaluate their weak points and tried to avoid making the same errors in the future. Therefore, they felt more confident in their writing.

The intermediate and low-proficiency students disclosed that it was useful, but difficult for them to self-monitor and question their work because they felt unsure whether or not their work was correct. They further highlighted that it did not mean that they could not self-monitor at all, but they sometimes did not feel certain of their ability to provide good annotations, especially on vocabulary, language use, and mechanics. They addressed that these three writing aspects were important to them and that they wanted to improve their writing more on these aspects. The following were sample data from the interviews on the self-monitoring strategy.

I think it was really good because it helped me gain more confidence in my writing. When I had problems that I was not sure about, I formulated some questions and asked my friend and she could clarify the problems or, at least, make me feel more confident to revise my work. The strategy also helped me think carefully and know my weak points. It was not too difficult to self-monitor. (Student \#9-High)

The strategy was useful and it helped me improve my essay writing skills. However, I think it was quite difficult because I had to think a lot and come up with annotations for my friends to give feedback to me and I could not see problems in my work, especially on vocabulary and grammar. (Student \#6 - Intermediate)

I was not sure whether my writing was correct and that made it quite difficult to ask questions, especially on vocabulary, grammar, and mechanics. I wanted to improve these writing aspects, but I did not know what to ask. (Student \#1 - Low)

In terms of the peer feedback strategy, most students reported that the strategy was good, easier than the self-monitoring, and they liked it, especially the intermediate and low-proficiency students. This was because the strategy allowed them to talk more openly and use more casual language with their partners. Also, they sometimes could benefit from the feedback on the aspects that they did not 
self-monitor well, for example, the vocabulary and language use. However, some of them, especially the high-proficiency students reported that they did not like the strategy. They revealed that the strategy had drawbacks where their partners did not provide useful peer feedback, espeically on the aspect of grammar to them because of their limitation of language knowledge. This was why some of the high-proficiency students did not easily accept the feedback to use in their writing.

Whether or not the strategy improved their essay writing skills, the high-proficiency students reported that they did not benefit from the strategy that much. This was because, although the questionnaire data suggested otherwise, the majority of their partners were at the intermediate and low proficiency levels, thus, unable to provide useful feedback to the high-proficiency students, particularly on the vocabulary, language use, and mechanics. Although they could benefit from the feedback given on content and organization, they had to evaluate the feedback carefully before using it in their work checking whether or not the feedback would be valid and useful to them. If they were not sure about the given feedback or the feedback did not really answer their questions, they would not use it. Rather, they would stick to the old versions of their writing, ask the teacher for feedback, or check the answers from the Internet, books, or dictionaries.

The intermediate and low-proficiency students revealed that they were able to benefit from the strategy when paired with students of a higher proficiency level, thus being more satisfied with the strategy. They could use feedback on vocabulary, language use, and mechanics to revise their writing. Although these students were likely to benefit more than the high-proficiency students, they revealed that they still had to evaluate the feedback before using it in their work as well. If they were not sure about the provided feedback, they would ask the teacher for accuracy and appropriateness. The following were sample data from the interviews on the peer feedback strategy.

I didn't like the strategy because my partner didn't give her all in the feedback and didn't really answer my questions. Some feedback wasn't really beneficial to me at all and I wouldn't trust her feedback either. I would like the teacher to give feedback to me instead. (Student \#8-High)

I liked this strategy. It was easier than self-monitoring. My partner could see my errors in my writing and I could revise and edit my work based on the feedback and comments. However, I didn't believe all the feedback given by my partner. When I wasn't sure about the feedback, I asked the teacher about it and re-checked before revising or editing my work. (Student \#4 - Intermediate)

I think it was good. My partner could detect errors that I did not ask for such as verb tense and mechanics and I could benefit from her feedback. (Student \#1-Poor)

Overall, students were satistied with the strategies. Although some students preferred one strategy to another, i.e., high-proficiency students, due to limitation of language knowledge and possible low self-efficacy of their partners, it was evident that these two strategies could help students learn writing collaboratively, gradually develop their critical thinking skills, and improve their writing skills.

\section{Discussion}

Findings suggest that although students were satisfied with the self-monitoring and peer feedback strategies in general, there were challenges when implementing these strategies in the EFL writing class where the students' language abilities were mixed.

\subsection{Possible low self-efficacy for writing}

Based on the results from the questionnaire in the areas of self-monitoring (item 1, 2, 4, 5, 10, and 11) and the area of peer feedback (item 13), we can see the lowest among high average scores. This evidence perhaps emphasizes the challenge in implementing the self-monitoring and peer feedback strategies in a class where the majority of students are in the low-intermediate level due to possible low self-efficacy for writing and collaborating with peers due to their limitation of language knowledge.

Studies on self-efficacy levels in writing (Garcia \& De Caso, 2006; Pajares, 2010; Pajares \& Cheong, 2003) showed that students with improved self-efficacy were able to learn writing better than those who had low self-efficacy. However, high self-efficacy alone might not guarantee students' writing improvement and their satisfaction toward using the strategies as it involved other factors such as teaching styles and methods, feedback, etc. (Magogwe, Ramoroka \& Mogana-Monyepi, 2015). Thus, this implies that boosting students' self-efficacy for writing together with other aspects such as teaching methods, teacher, content, etc. may contribute to students' satisfaction toward writing classes that employ the self-monitoring and peer feedback strategies.

\subsection{Limitation of language knowledge}

Evidence from the interview where the intermediate and low-proficiency students addressed that they found it difficult to self-monitor on vocabulary, language use, and mechanics, whereas the high-proficiency student did not trust in the feedback given by lower-proficiency peer also suggests that the intermediate and low-proficiency students might feel that their limited language knowledge did not 
fully empower them to comment, while the high-proficiency students might have preferred the teacher to provide feedback instead. Research (Chinnawongs, 2001; Lee, 2005 \& 2008) on students' perceptions on peer feedback and teacher feedback found that students, especially of the low-proficiency level, might feel constrained by their weakness of English so it limited their ability to comment on their peers' work, and they wanted teachers to provide feedback instead or tended to depend upon teacher support. This suggests that although content and organization are major and important writing aspects, further training on using these strategies emphasizing language knowledge is also needed and should not be overlooked.

\subsection{Lack of proper understanding of the characteristics of the writing skill and learning how to write}

Evidence from the interview where students, especially the high and intermediate students, reported that they preferred the teacher to give feedback to them suggests that students might lack of proper understand of the characteristics of the writing skill and learning how to write where writing is done for a wider audience, not only for the teacher. Students can learn from one another through feedback they get from peers and improve their work. As autonomy and collaboration are important aspects to be encouraged in writing classes (Hyland, 2000), it is important to renew the beliefs of students that although the teacher has more experience and is the main source of writing knowledge, they can certainly learn from one another in the area of content and world knowledge.

\section{Conclusion}

This study shows that students were satisfied with the self-monitoring and peer feedback strategies in general. Although the two strategies were found to come with challenges when they were implemented with mixed-ability students in the EFL writing class due to a possible low efficacy for writing, limitation of language knowledge, and lack of proper understanding of the characteristics of the writing skill and learning how to write, it provided insights into strengthening any writing course that specially emphasized using these two strategies, which may contribute to success in teaching and learning writing in the EFL context.

\section{References}

Chen, X. (2009). "Self-monitoring" feedback in English writing teaching. Research in Theoretical Linguistics, 3(12), 109-117.

Chinnawongs, S. (2001). In search of an optimal writing feedback strategy. PASAA, 31, $27-43$.

Garcia, J.N., \& De Caso, A.M. (2006). Changes in writing self-efficacy and writing products and processes through specific training in the self-efficacy beliefs of students with learning disabilities. A Contemporary Journal, 4(2), 1-27.

Gielen, S., Peeters, E., Dochy, F., Onghena, P., \& Struyven, K. (2010). Improving the effectiveness of peer feedback for learning. Learning and Instruction, 20(4), 304-315.

Hyland, F. (2000). ESL writers and feedback: Giving more autonomy to students. Language Teaching Research, 4(1), 33-54.

Lee, I. (2005). Error corrections in the L2 writing classroom: What do students think? TESL Canada Journal, 22(2), 1-16.

Lee, I. (2008) Student reactions to teacher feedback in two Hong Kong secondary classrooms. Journal of Second Language Writing, 17(3), 144-164.

Magogwe, J.M., Ramoroka, B.T., \& Mogana-Monyepi, R. (2015). Developing student-writers' self-efficacy beliefs. Journal of Academic Writing, 5(2), 20-28.

Pajares, F. (2010). Self-efficacy beliefs, motivation, and achievement in writing: A review of the literature. Reading \& Writing Quarterly, 19(2), 139-158, DOI: 10.1080/10573560308222

Pajares, F., \& Cheong, Y.F. (2003). Achievement goal orientations in writing: a development perspective. International Journal of Education Research, 39(4-5), 437-455.

Rollinson, P. (2005). Using peer feedback in the ESL writing class. ELT Journal, 59(1), 23-31.

Xiang, W. (2004). Encouraging self-monitoring in writing by Chinese students. ELT Journal, 58(3), 238-246.

Yu, S., \& Hu, G. (2016). Can higher-proficiency L2 learners benefit from working with lower-proficiency partners in peer feedback? Teaching in Higher Education, DOI: 10.1080/13562517.2016.1221806 